\title{
Anxiety Sensitivity Mediates Relations Between Mental Distress Symptoms and Medical Care Utilization During COVID-19 Pandemic
}

\author{
Juliana M. B. Khoury ${ }^{1} \cdot$ Margo C. Watt ${ }^{1,2} \cdot$ Kim MacLean $^{1}$
}

Accepted: 9 June 2021/ Published online: 21 June 2021

(C) Springer Nature Switzerland AG 2021

\begin{abstract}
Anxiety and uncertainty are common during pandemics. The present study extended previous pandemic research by investigating the role of two transdiagnostic risk factors - anxiety sensitivity (AS: fear of physiological anxiety or "fear of fear"; Reiss \& McNally, 1985) and intolerance of uncertainty (IU; Buhr \& Dugas, 2009) — in explaining relations between mental distress symptoms and behavioural responding during the COVID-19 pandemic. Student and community-based participants ( $N=457$; $87.6 \%$ female) were recruited between May and July 2020 to complete measures of anxiety (health, panic, general), depression, and stress. Anxiety and related symptoms were found to be higher than in previous studies. Parallel mediation analyses showed that clinically meaningful levels of mental distress symptoms directly influenced safety behaviours and medical care utilization but also indirectly influenced the latter (vs. former) through AS-physical concerns (vs. IU). CBT interventions, targeting ASphysical concerns, may reduce mental distress symptoms during pandemic and prevent overuse of healthcare.
\end{abstract}

Keywords COVID-19 • Anxiety sensitivity · Intolerance of uncertainty · Medical care utilization · Panic

Coronavirus disease 2019 (COVID-19) was declared a pandemic on March 11, 2020. COVID-19 is a novel member of a large family of viruses responsible for diseases ranging from the common cold to severe respiratory diseases, such as severe acute respiratory syndrome (SARS) and Middle East respiratory syndrome (MERS) (see BC

Juliana M. B. Khoury

x2016pru@stfx.ca

1 Department of Psychology, St. Francis Xavier University, Antigonish, Nova Scotia, Canada

2 Departments of Psychology/Neuroscience and Psychiatry, Dalhousie University, Halifax, Nova Scotia, Canada 
Centre for Disease Control, 2020). The principal mode of transmission is through exposure to respiratory droplets carrying the infectious virus (CDC, 2020). To date, cases of COVID-19 exceed 134 million globally and are responsible for over 2.9 million deaths (WHO, April 10, 2021).

The defining characteristics of pandemics - global reach, unexpected emergence, invisibility, involuntary exposure, and potential lethality - are bound to trigger greater fear and uncertainty than do more familiar threats, such as influenza (Balderston et al., 2013). Not surprisingly, elevations in symptoms of mental distress (e.g., anxiety, depression, stress) are common during pandemics. During the 2009-2010 H1N1 (swine flu) pandemic, Rubin et al. (2009) found that nearly one-quarter (23.8\%) of a British sample reported significant anxiety. At the same time, other researchers found that people with poor tolerance for uncertainty experienced the greatest anxiety and were less likely to believe they could do anything to protect themselves (Taha et al., 2014). Recently published findings on mental health impacts of COVID-19 confirm these findings. In a nationally representative sample of over 1800 Canadians surveyed prior to June 2020, Dozois and Mental Health Research Canada (2020) found that self-reported "high" and "extremely high" anxiety levels had quadrupled (from 5 to 20\%) and self-reported depression had more than doubled (from 4 to 10\%) since the onset of COVID-19. Excessive fears of COVID-19 have been linked to excessive avoidance and serious distress (Taylor, Landry, Paluszek, \& Asmundson, 2020a). In a sample of Canadian and American participants, Taylor, Landry, Paluszek, Fergus, et al. (2020b) found that $38 \%$ of participants experienced some level of distress and another $16 \%$ experienced a high degree of distress. This is consistent with the literature from other countries. According to the CDC (Czeisler et al., 2020), 40.9\% of American adults reported at least one mental health condition (i.e., depression, anxiety, trauma) as a result of the pandemic. In their systematic review of COVID-19 studies conducted in Europe and Asia, Salari et al. (2020) reported elevated levels of stress (29.6\% of the sample), anxiety (31.9\%), and depression $(33.7 \%$ ), suggesting a need to focus not only on physical health concerns but also mental health concerns during the COVID-19 pandemic.

While increased anxiety during pandemics can lead to increased safety behaviours such as hand washing (Rubin et al., 2009), excessive anxiety and other mental distress symptoms can impair functioning and lead to maladaptive coping. Maladaptive coping can enhance one's perceived need for medical attention and reassurance, leading to overuse of precious healthcare services — services already suffering pre-pandemic from the effects of "too much medicine" (see Moynihan et al., 2020, p. 1). Efforts to identify risk factors for impairment during pandemics have focused on psychological risk factors associated with poor mental health outcomes. One such factor is anxiety sensitivity (AS), a dispositional fear of physiological sensations commonly associated with anxiety, such as increased heart rate, respiration, and perspiration (Reiss \& McNally, 1985). Individuals high in AS are inclined to catastrophize the meaning of these sensations, thinking they portend negative physical consequences (e.g., heart attack), cognitive consequences (e.g., loss of control), and/or social consequences (e.g., embarrassment). High AS elevates attention to physiological sensations, amplifies their aversiveness, and leads to efforts to escape and avoid situations and stimuli that elicit feared sensations. These can include emotional distress (Allan et al., 2015), social anxiety (Taylor et al., 2007), physical exercise (Sabourin et al., 2011), and sexual activity (Gerrior et al., 2015). 
At the height of the H1N1 (swine flu) pandemic (2009-2010), Wheaton et al. (2012) investigated AS and other potential psychological predictors of swine flu anxiety with a sample of undergraduates $(\mathrm{N}=315)$. AS-physical concerns, but not cognitive or social concerns, correlated positively with swine flu anxiety. Health anxiety, disgust sensitivity, and contamination cognitions, but not AS-physical concerns, were found to be significant individual predictors of anxiety. With a similar sample of undergraduates ( $N=393$ ), Brand et al. (2013) found that AS mediated the relationship between obsessive compulsive symptoms (not beliefs) and swine flu anxiety. Disgust sensitivity mediated relations between both obsessive-compulsive symptoms and beliefs, and swine flu anxiety, but path models indicated that AS was the more potent mediator. The study was inadequately powered to simultaneously test multiple mediators.

During the Ebola epidemic in 2014, Blakey et al. (2015) investigated psychological predictors of Ebola-related anxiety and safety behaviours among undergraduates $(\mathrm{N}=107)$. Again, AS-physical concerns emerged as a significant risk factor, along with disgust sensitivity, contamination cognitions, body vigilance, and general distress; all correlated significantly and positively with Ebola-related anxiety. Notably, AS-physical concerns and overestimations of contamination severity (vs. contamination likelihood) were found to be unique predictors of Ebola-related fears and safety behaviours.

Subsequently, during the Zika virus pandemic (2015-2016), Blakey and Abramowitz (2017) investigated psychological predictors of health and Zika-related anxiety, including AS, with a sample of American university affiliates $(\mathrm{N}=216)$. Results showed that more accurate knowledge of the virus and overestimations of contamination severity (vs. likelihood) uniquely predicted Zika-related anxiety. AS dimensions were not found to predict Zika-related anxiety, however, but the consistent finding of overestimation of disease severity led to the suggestion that other variables, such as intolerance of uncertainty (IU), warranted investigation.

Whereas AS is a specific fear of physiological arousal (i.e., "fear of fear"; Reiss \& McNally, 1985), IU is a more general fear of the unknown (Buhr \& Dugas, 2009; Carleton, 2016). People with high IU find unforeseen events and lack of adequate information to be distressing. Both AS and IU are considered transdiagnostic factors factors presumed to underlie and be common to various forms of psychopathology. High AS, for example, has been linked to anxiety, especially panic and health anxiety, as well as related disorders, including mood, stress, PTSD, and substance use (see Olatunji et al., 2009; Olatunji \& Wolitzky-Taylor, 2009). Interventions designed to reduce AS, such as Watt and Stewart's (2008) brief cognitive behavioural therapy (CBT-AS), have been found to yield positive effects across disorders (see Olthuis et al., 2014, 2015; Watt et al., 2005, 2006). Similarly, IU has been linked to various psychological disorders, including anxiety, depression, obsessive-compulsive disorder, and eating disorders (Carleton et al., 2012; Renjan et al., 2016; Toffolo et al., 2014). CBT-targeting IU (CBT-IU) has been found to be effective in treating generalized anxiety disorder (Dugas et al., 2003; Gosselin et al., 2006).

Both AS and IU are commonly associated with health anxiety (see Wright et al., 2016), which is a prominent focus of most studies on pandemic fears. McKay et al. (2020) found that the AS-physical concerns predicted COVID-19-related health anxiety, and both Tull et al. (2020) and Wheaton et al. (2020) found associations between IU and health anxiety concerning COVID-19. Fergus and Bardeen (2013) found that both AS and IU concurrently predicted health anxiety beyond both negative 
affect and each other, but concluded that AS-physical concerns may play a more critical role in the etiology of health anxiety than IU. Other research (e.g., Olatunji et al., 2009) has linked AS-physical concerns to certain facets of health anxiety (e.g., body vigilance) versus others (e.g., illness severity). Individuals inclined to be health anxious commonly engage in reassurance- and safety-seeking behaviours, as well as greater utilization of healthcare services (see Barsky et al., 2001; Conroy et al., 1999; Creed, 2011; Fergus et al., 2015, Rask et al., 2016). Horenstein et al. (2019) found that health anxiety was associated with greater odds of seeking general medical care over the past 6 months among individuals with elevated levels of both AS and IU. The findings suggested a synergistic effect of AS and IU, whereby the relationship between health anxiety and health care utilization is strengthened by AS but only within the context of high (vs. low) IU.

The present study sought to extend previous pandemic research by more closely examining the respective roles of AS-physical concerns and IU in explaining relations between mental distress symptoms and behavioural responses during the COVID-19 pandemic. More specifically, we wanted to test whether each or both transdiagnostic factors would mediate relations between self-reported and clinically meaningful levels of mental distress symptoms (i.e., health anxiety, panic anxiety, general anxiety, depression, and/or stress) and the behavioural responses of engaging in safety behaviours and utilizing medical resources. It was predicted that mental distress symptoms would yield a direct effect on both types of behavioural responses but also an indirect effect through both AS-physical and IU, with AS-physical being the more potent mediator.

\section{Method}

\section{Participants}

Participants were 457 adults, most of whom were female (87.6\%) and Euro-Canadian $(89.0 \%)$, ranging in age from 18 to 85 years with a mean age of 37.42 (SD = 16.77). Community-based participants $(\mathrm{N}=358,88.1 \%$ female) were recruited through social media and online advertising websites; students $(\mathrm{N}=99,85.9 \%$ female) were recruited through email sent via the university student listserv. To be included in the study, participants had to be at least 18 years of age and able to read English. The estimated literacy level necessary for the survey was Grade 7 as determined by the Flesch Kincaid Reading Ease measure.

\section{Procedure}

Data were collected between April 27 and July 22, 2020, during the first wave of COVID-19. Following clearance from the university's Research Ethics Board, participants were invited to complete an online survey via Qualtrics Survey Software. The survey began by obtaining informed consent, followed by a series of demographics questions, then the measures. 


\section{Measures}

\section{Descriptive Measures}

Demographics Questionnaire Data were collected on participant sex, gender, ethnicity, education, and occupation.

COVID-19 Fear Index (CFI) Following from the work of previous pandemic researchers (Blakey \& Abramowitz, 2017; Blakey et al., 2015; Brand et al., 2013; Wheaton et al., 2012), the CFI was constructed for the current study to assess participants' level of fear concerning COVID-19. It included six questions (e.g., "To what extent are you concerned about COVID-19?") to which participants responded using a Likert scale ranging from 1 ("Not at all") to 5 ("Extremely"). Scores from each item were summed to provide a total score that ranged from 6 to 30 . In the present study, the CFI demonstrated good internal consistency $(\alpha=.79)$ and the distribution of item scores was free of significant skew $(<.49)$ and kurtosis $(<1.12)$.

\section{Predictor Variable: Mental Distress Symptoms}

A dichotomous variable was created to reflect participants who self-reported clinically meaningful symptoms of either health anxiety (SHAI); panic anxiety (PAQ-IV); general anxiety, depression, or stress (DASS-21) with $1=$ at or above critical cut-off score for each measure or $0=$ below critical cut-off score for each measure. This resulted in 208 participants (45.5\% of the sample) being categorized as reporting at least one clinically meaningful mental distress symptom. This variable was the predictor in all mediation analyses. Out of 457 participants, $54.5 \%(\mathrm{~N}=249)$ reported no clinically meaningful symptoms; $45.5 \%(\mathrm{~N}=208)$ reported at least one clinically meaningful symptom; $25.2 \%(\mathrm{~N}=115)$ reported at least two clinically meaningful symptoms; $13.8 \%(\mathrm{~N}=63)$ reported at least three clinically meaningful symptoms; and $5.7 \%$ $(\mathrm{N}=26)$ reported at least four clinically meaningful symptoms. (Numbers and percentages reflect overlap across categories).

Depression, Anxiety, and Stress Scale-21 (DASS-21; Lovibond \& Lovibond, 1995) The DASS-21 is composed of three 7-item subscales measuring respondents' levels of depression (items 3, 5, 10, 13, 16, 17, and 21; e.g., "I felt down-hearted and blue"), anxiety (items 2, 4, 7, 9, 15, 19, and 20; e.g., "I felt I was close to panic"), and stress (items 1, 6, 8, 11, 12, 14, and 18; e.g., "I found it difficult to relax") respectively. Participants rated the extent to which each statement applied to them in the past week using a Likert scale ranging from 0 ("Did not apply to me at all") to 3 ("Applied to me very much or most of the time"). Scores for each subscale are found by doubling and summing all corresponding items, and a total score is determined by doubling and summing all 21 items (subscale range $=0-42$; total range $=0-126$ ). Both the subscales and the overall measure have been found to have acceptable internal consistency, construct validity, and convergent and discriminant validity (Henry \& Crawford, 2005). In the present study, the DASS-21 demonstrated very good-to-excellent internal 
reliability with Cronbach's alphas ranging from 0.86 (DASS-Anxiety) to 0.89 (DASSStress) and 0.90 (DASS-Depression).

Clinically meaningful cut-off scores: According to Lovibond and Lovibond (1995), the cut-off scores for "extremely severe" symptoms are $28+$ for the depression subscale (present sample $=20.8 \%$ ), 20+ for the anxiety subscale $(25 \%)$, and $34+$ for the stress subscale $(13.6 \%)$.

Short Health Anxiety Inventory (SHAl; Salkovskis et al., 2002) The SHAI is an 18-item measure of health anxiety, composed of two sections. The first consists of 14 items and measures respondents' attitudes and focus regarding their health. Each item consists of four statements in ascending severity (e.g., "I do not worry about my health", "I occasionally worry about my health", "I spend much of my time worrying about my health", "I spend most of my time worrying about my health"). For each item, participants selected the statement which they felt best captured their attitude. Original instructions give the respondent the option of selecting more than one statement if applicable, but participants were asked to select the best option in this study. Section 2 consists of four items, in the same format, but this time concerning a hypothetical scenario: participants are asked to imagine themselves with a serious illness, and the items measure how participants think they would feel if such were the case (e.g., "If I had a serious illness I would still be able to enjoy things in my life quite a lot", "If I had a serious illness I would still be able to enjoy things in my life a little", "If I had a serious illness I would be almost completely unable to enjoy things in my life", "If I had a serious illness I would be completely unable to enjoy life at all"). Zero points are allotted for the first statement, one for the second, two for the third, and three for the fourth, with the measure being scored by summing the 18 items, with a possible range of 0 to 54. The SHAI has strong psychometric properties (Alberts et al., 2013). In the present study, the SHAI demonstrated excellent internal reliability with a Cronbach's alpha of 0.90 .

Clinically meaningful cut-off scores: According to Alberts et al. (2013), a score of $28+$ suggests clinically diagnosable health anxiety. In the present sample, $10.9 \%$ scored 28 or above.

Panic Attack Questionnaire-IV (PAQ-IV; Norton et al., 2008) The PAQ-IV measures whether participants have ever had a panic attack, and, if so, the frequency with which they have recently occurred. It is a self-report measure: participants respond either yes or no to whether they have ever had a panic attack, and those who respond affirmatively are then asked to indicate how many they have had in the past year $(0,1-2,3-5$, $6-10$, or over 10$)$, and how many in the past 2 weeks $(0,1-2,3-5,6-10$, or over 10$)$. The PAQ-IV has strong concurrent validity (Norton et al., 2008).

Clinically meaningful cut-off scores: $\mathrm{N}=24$ or $5.3 \%$ of the sample reported $3+$ panic attacks in the past 2 weeks ( 92 reported at least one panic attack in the past 2 weeks, 18 reported 3-5, 5 reported 6-10, and 1 reported more than 10). Inter-item 
correlations in the present study ranged from .21 (ever and past 2 weeks) to .37 (ever and past year) to .70 (between 2 weeks and past year).

\section{Mediator Variables}

Anxiety Sensitivity Index-3 (ASI-3; Taylor et al., 2007) The ASI-3 is an 18-item selfreport questionnaire that measures AS across each of its three dimensions, through three 6-item subscales: Physical Concerns (items 1, 6, 9, 11, 13, and 17; e.g., "When my throat feels tight, I worry that I could choke to death"), Cognitive Concerns (items $2,5,10,14,16$, and 18; e.g., "When my mind goes blank, I worry there is something terribly wrong with me"), and Social Concerns (items 1, 6, 9, 11, 13, and 17; e.g., "It scares me when I blush in front of people"). Participants rate the extent to which they agree or disagree with each statement on a Likert scale ranging from 0 ("very little") to 4 ("very much"). Subscale and total scores are calculated by summing the appropriate items (subscale range $=0-24$; total range $=0-72$ ). The ASI-3 has strong internal consistency and convergent, discriminant, and criterion-related validity (Taylor et al., 2007). In the present study, the ASI-3 demonstrated very good to excellent internal reliability with Cronbach's alphas ranging from 0.88 (AS-social concerns) to 0.90 ( ASphysical concerns) to 0.93 (AS-cognitive concerns) and 0.94 for AS-Global.

Intolerance of Uncertainty Scale-12 (IUS-12; Carleton et al., 2007) The IUS-12 is a 12item self-report questionnaire measuring how troubled respondents are by uncertainty. Each item consists of a statement (e.g., "When it's time to act, uncertainty paralyses me") which participants rate based on how strongly they believe the statement applies to them, using a 5-point Likert scale that ranges from 1 ("Not at all characteristic of me") to 5 ("Entirely characteristic of me"). Scoring involves summing the 12 items, with scores ranging from 12 to 60 . The IUS-12 has strong internal consistency, and a strong correlation with the original IUS (Carleton et al., 2007). In the present study, the IUS-12 demonstrated excellent internal reliability with a Cronbach's alpha of 0.92.

\section{Dependent Variables}

COVID-19 Safety Behaviours Checklist (CSBC) The CSBC was constructed for the current study by adapting and modifying Wong and Sam's (2011) scale from their study on the H1N1 pandemic. The CSBC was used to assess the extent to which participants were performing positive safety behaviours regarding COVID-19. It consisted of 10 statements describing various safety behaviours (e.g., "I wash my hands frequently"), which participants rated using a Likert scale ranging from 1 ("Strongly disagree") to 5 ("Strongly agree"). Scores were summed to obtain a total score ranging between 10 and 50. In the present study, the 10-item CSBC demonstrated good internal reliability with a Cronbach's alpha of 0.72 . An exploratory factor analysis produced a 2-factor solution with Factor 1 (6 items) capturing Approach behaviours (e.g., washing hands, covering coughs) and Factor 2 (4 items) capturing Avoidance behaviours (e.g., avoiding public places and public transportation). Each factor had 
questionable reliability (Cronbach' alphas of .61 and .68, respectively) so analysis was conducted on the full scale.

Medical Utilization Questionnaire (MUQ; Abramowitz et al., 2007) The original MUQ assesses utilization of both professional healthcare (emergency and specialist physicians; 20 items) and 10 self-care resources (e.g., reading about the virus, checking vital signs, using OTC medications and herbal supplements; 10 items). For the purposes of the present study, we used the 10 self-care items plus two items pertaining to seeking professional healthcare (visited hospital; health care clinic or doctor's office). We also modified the MUQ to reflect COVID-19 protocols in Canada (i.e., calling 811, the COVID-19 phone line). For each of the 12 items, respondents were asked to rate how often they performed each behaviour in the past month, using a Likert scale ranging from 0 ("Never out of concern for my health (not at all)") to 4 ("All the time out of concern for my health (every day)"). Scores were summed to obtain a total score which could range from 0 to 48. In the present study, the 12-item MUQ demonstrated good internal reliability with a Cronbach's alpha of 0.77 .

\section{Data Analytic Strategy}

All analyses were conducted with SPSS 26. Following computation of descriptive statistics, correlation analyses were conducted between all measures. Parallel mediation regression analyses were conducted using PROCESS (Hayes, 2013) to test for mediation effects of AS-physical concerns and IUS on the relationship between mental distress symptoms (IV), and COVID-19 safety behaviours and medical care utilization (DVs). See Fig. 1.

\section{Results}

\section{Data Screening}

Participant data were screened to assess concordance with the statistical assumptions of linearity, normality, and homoscedasticity. Skewness and kurtosis levels for two variables - CSBC and MUQ - exceeded the generally acceptable range of $<2$. An examination of outliers identified three potentially influential outliers; once they were removed, the distributions of scores for all measures were free of significant skew $($ all $<$ $1.07)$ and kurtosis (all < 1.09).

\section{Descriptive Statistics}

See Table 1 for a summary of results. As compared to previous pandemic studies, levels of AS-physical concerns in the present sample $(M=7.30, S D=5.88)$ were significantly higher than those found by Wheaton et al. (2012): $\mathrm{M}=3.63$ (4.14), $t(770)$ $=9.56,95 \%$ CI $[2.92,4.42], p<.000 ;$ Blakey and Abramowitz (2017): $\mathrm{M}=4.42$ (4.52), $t(671)=6.36,95 \%$ CI [1.99, 3.77], $p<.000$; and Blakey et al. (2015): $\mathrm{M}=4.34$ (4.29), $t(562)=4.91,95 \%$ CI $[1.78,4.14], p<.001$. Similarly, intolerance of 


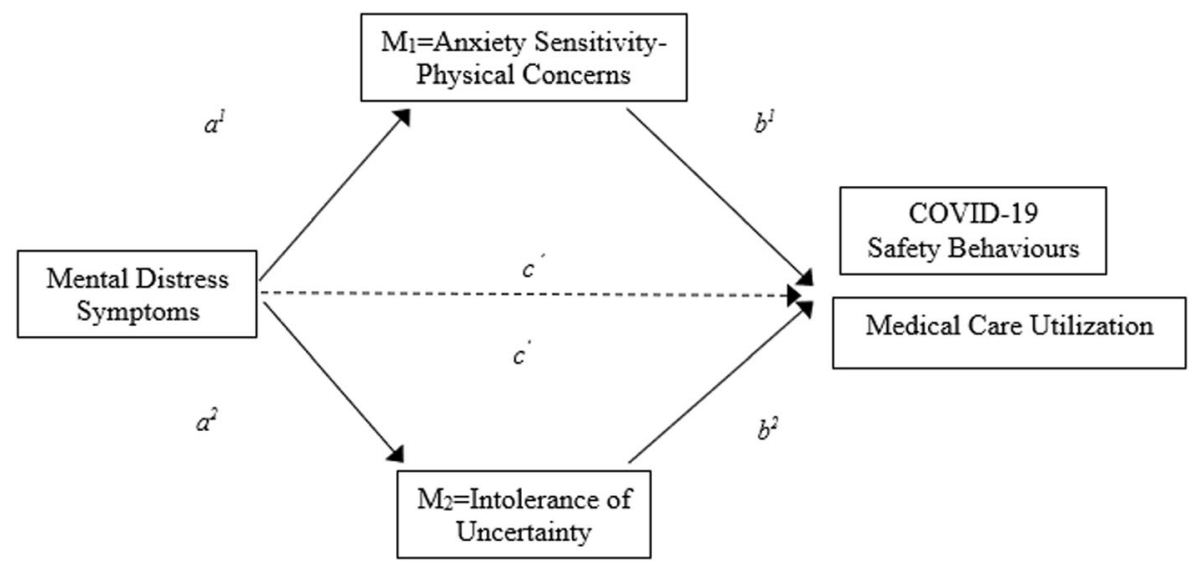

Fig. 1 Conceptual model of multiple parallel mediation analyses. Note: Examining the direct effect of mental distress symptoms on COVID-19 safety behaviours and Medial Care Utilization (separately), as well as indirect effects via the physical concerns dimension of anxiety sensitivity and intolerance of uncertainty (adapted from Hayes, 2018)

Table 1 Descriptive statistics for variables of interest with clinical cut-off scores for mental distress symptoms $(\mathrm{N}=457)$

\begin{tabular}{|c|c|c|c|c|c|}
\hline Variable & M & $\mathrm{SD}$ & Range & Clinical Cut-Off (CC) & $\%$ meeting $\mathrm{CC}$ \\
\hline $\operatorname{Sex}(F)$ & $87.6 \%$ & & & & \\
\hline Age & 37.42 & 16.77 & $18-85$ & & \\
\hline CFI & 18.86 & 4.63 & $8-30$ & & \\
\hline AS-Total & 22.00 & 16.10 & $0-72$ & & \\
\hline AS-Physical & 7.30 & 5.88 & $0-24$ & & \\
\hline AS-Cognitive & 5.95 & 6.31 & $0-24$ & & \\
\hline AS-Social & 8.77 & 6.66 & $0-24$ & & \\
\hline IUS-12 & 33.34 & 10.43 & $12-60$ & & \\
\hline SHAI & 16.84 & 8.08 & $1-52$ & $\geq 28$ & $10.9 \%$ \\
\hline PAQ Lifetime & $65.8 \%$ & & & & \\
\hline PAQ Past 2 weeks & $34.9 \%$ & & & $\geq 3$ in past 2 weeks & $5.3 \%$ \\
\hline DASS-Depression & 16.79 & 10.91 & $0-42$ & $\geq 28$ & $20.8 \%$ \\
\hline DASS-Anxiety & 12.07 & 10.15 & $0-42$ & $\geq 20$ & $25 \%$ \\
\hline DASS-Stress & 19.61 & 11.12 & $0-42$ & $\geq 34$ & $13.6 \%$ \\
\hline CSBC & 41.09 & 5.65 & $18-50$ & & \\
\hline MUQ & 7.75 & 5.56 & $0-31$ & & \\
\hline
\end{tabular}

Note: CFI COVID-19 Fear Index, AS-Tot Anxiety Sensitivity Index 3 total score, AS-Physical physical concerns of Anxiety Sensitivity Index-3, AS-Cognitive cognitive concerns of Anxiety Sensitivity Index-3, ASSocial social concerns of Anxiety Sensitivity Index-3, IUS-12 Intolerance of uncertainty Scale-12-item version, SHAI Short Health Anxiety Index, PAQ Panic Attack Questionnaire-IV, DASS-Dep Depression Anxiety Stress Scale-21-item version depression subscale, DASS-Anx Depression Anxiety Stress Scale-21item version anxiety subscale, DASS-Stress Depression Anxiety Stress Scale-21-item version stress subscale, CSBC COVID-19 Safety Behaviours Checklist, $M U Q$ Medical Utilization Questionnaire 
uncertainty as measured by the IUS-12 was significantly higher in this sample $(M=$ 33.34, $S D=10.43$ ) as compared to results reported by O'Bryan and McLeish (2017): $\mathrm{M}=29.57$ (9.39), $t(1080)=6.22,95 \% \mathrm{CI}[2.58,4.96], p<.000$, and in Carleton et al.'s (2012) community-based sample: $\mathrm{M}=29.53$ (10.96), $t(1026)=5.66,95 \%$ CI $[2.49$, 5.13], $p<.000$.

Levels of health anxiety as measured by the SHAI also were significantly higher in the present sample $(M=16.84, S D=8.08)$ as compared to Wheaton et al. $(2012): \mathrm{M}=$ $12.03(6.75), t(770)=8.68,95 \% \mathrm{CI}[3.72,5.90], p<.000$, and Blakey and Abramowitz (2017): $\mathrm{M}=12.44$ (5.75), $t(671)=7.19,95 \%$ CI [3.20, 5.60], $p<.000$. Wheaton et al. (2012) also used the DASS-21 to assess general depression, anxiety, and stress. In comparison, the present sample (depression: $M=16.79, S D=10.91$; anxiety: $M=$ 12.07, $S D=10.15$; stress: $M=19.61, S D=11.12$ ) demonstrated significantly higher levels across each subscale - depression: $\mathrm{M}=6.72(7.27), t(770)=14.33,95 \% \mathrm{CI}$ [8.69, 11.45], $p<.000$; anxiety: $\mathrm{M}=5.42(6.03), t(770)=10.43,95 \%$ CI $[5.40,7.90], p$ $<.000$; and stress: $\mathrm{M}=11.18(7.97), t(770)=11.56,95 \%$ CI $[7.00,9.86], p<.000$.

Utilization of medical resources as measured by part 2 of the MUQ were significantly higher in the present sample $(M=7.75, S D=5.56)$ as compared to Abramowitz et al.'s (2007) non-clinical sample: $M=0.55(0.47), t(897)=29.90,95 \%$ CI [7.17, $8.22), p<.000$, and to Fergus and Valentiner's (2010) non-clinical sample: $M=6.46$ $(5.37), t(958)=3.66,95 \%$ CI $[0.60,1.98], p<0.01$. Levels of safety behaviours in the current sample as measured by the CSBC $(M=41.09, S D=5.65)$ were significantly higher than those measured with the Ebola Safety Behaviors Checklist (ESBC) in Blakey et al.'s (2015) study: $\mathrm{M}=9.85$ (11.63), $t(562)=40.57,95 \%$ CI $[29.73,32.75]$, $p<.000$. Direct comparison cannot be made, however, as the ESBC is a 9-item measure for which each item is scored on a scale of 0-10 (range $=0-90$ ), whereas the CSBC is a 10-item measure with each item scored on a 1-5 scale (range $=10-50$ ). Items were similar, however, so comparison is nevertheless useful.

\section{Bivariate Correlations}

As illustrated in Table 2, elevated levels of mental distress symptoms correlated significantly and positively with higher levels of AS-physical concerns, IUS, and COVID-related fears. Mental distress symptoms also correlated significantly and positively with engagement in COVID safety behaviours and medical care utilization (e.g., accessing medical information, attention, and treatments). AS-physical concerns correlated significantly and positively with all predictor and dependent variables. IUS correlated significantly and positively with all predictor variables and medical care utilization and trended toward significance with COVID safety behaviours $(p=.06)$. All measures of mental distress symptoms correlated significantly and positively with predictor and dependent variables.

\section{Mediation Analyses}

Results of parallel mediation analyses using PROCESS (Hayes, 2013) are presented in Tables 3 and 4 and Figs. 2 and 3. Results showed that mental distress symptoms (MDSx) directly affected COVID safety behaviours (CSB) $(\mathrm{c}=1.67, p=.002)$. More specifically, participants with clinically meaningful levels of mental distress symptoms 
Table 2 Bivariate correlations between variables of interest $(\mathrm{N}=457)$

\begin{tabular}{|c|c|c|c|c|c|c|c|c|c|c|c|}
\hline Variable & 1 & 2 & 3 & 4 & 5 & 6 & 7 & 8 & 9 & 10 & 11 \\
\hline 1. MD-Sx & --- & & & & & & & & & & \\
\hline 2. AS-Phys & $.51^{* * *} *$ & --- & & & & & & & & & \\
\hline 3. IUS- 12 & $.53^{* * * *}$ & $.47 * * *$ & --- & & & & & & & & \\
\hline 4. SHAI & $.50 * * *$ & $.60 * * *$ & $.51 * * *$ & --- & & & & & & & \\
\hline 5. PAQ & $.41^{* * * *}$ & $.35 * * *$ & $.30 * * *$ & $.31 * * *$ & --- & & & & & & \\
\hline 6. DASS-D & $.68^{* * *}$ & $.43 * * *$ & $.58 * * *$ & $.48 * * *$ & $.33 * * *$ & --- & & & & & \\
\hline 7. DASS-A & $.71 * * *$ & $.55 * * *$ & $.56^{* * * *}$ & $.51 * * *$ & $.48 * * *$ & $.64 * * *$ & --- & & & & \\
\hline 8. DASS-S & $.64^{* * * *}$ & $.41 * * *$ & $.58 * * *$ & $.47^{* * * *}$ & $.41 * * *$ & $.70 * * *$ & $.73 * * *$ & --- & & & \\
\hline 9. $\mathrm{CSBC}$ & $.15^{* *}$ & $.11 * *$ & .09 & $.12 *$ & $.12 *$ & .08 & $.17 * * *$ & $.13^{* * *}$ & -- & & \\
\hline 10. MUQ & $.40^{* * * *}$ & $.49 * * *$ & $.28 * * *$ & $.54 * * *$ & $.26^{* * * *}$ & $.27 * * *$ & $.47 * * *$ & $.38 * * *$ & $.17 * * *$ & -- & \\
\hline 11. CFI & $.35 * * *$ & $.38 * * *$ & $.43 * * *$ & $.45^{* * *}$ & $.26^{* * * *}$ & $.37 * * *$ & $.43 * * *$ & $.44 * * *$ & $.38 * * *$ & $.36^{* * *}$ & --- \\
\hline
\end{tabular}

Note: $M D$-Sx Mental Distress Symptoms, AS-Phys physical concerns of Anxiety Sensitivity Index-3, IUS-12 Intolerance of Uncertainty Scale-12, SHAI Short Health Anxiety Index, PAQ Panic Attack Questionnaire-IV, DASS-Dep Depression Anxiety Stress Scale-21-item version depression subscale, DASS-Anx Depression Anxiety Stress Scale-21-item version anxiety subscale, DASS-Stress Depression Anxiety Stress Scale-21item version stress subscale, CSBC COVID-19 Safety Behaviours Checklist, $M U Q$ Medical Utilization Questionnaire, CFI COVID-19 Fear Index

$* * * \mathrm{p}<.000 . * * \mathrm{p}<.01 . * \mathrm{p}<.05$

$(\mathrm{MDS} x=1)$ reported engaging in more COVID safety behaviours than other participants and this relationship remained significant after accounting for both mediators $\left(c^{\prime}=1.40\right.$, $p=.036$; confidence intervals 0.089 to 2.703). Participants who reported clinically meaningful levels of mental distress symptoms $(\mathrm{MDSx}=1)$ reported more fear of physiological sensations (AS-physical concerns) than other participants $(\mathrm{MDSx}=0$ ) $\left(\mathrm{a}^{1}=5.94, p=.000\right)$ and less tolerance of uncertainty $\left(\mathrm{a}^{2}=11.19, p=.000\right)$. Results, however, showed no indirect effects of MDSx on safety behaviours through either $\mathrm{M}_{1}$ (AS-physical concerns) or $\mathrm{M}_{2}$ (intolerance of uncertainty). $95 \%$ confidence intervals based on 10,000 bootstrap samples indicated that indirect effects through ASphysical concerns $\left(\mathrm{a}_{1} \mathrm{~b}_{1}=0.275\right)$ and IUS $\left(\mathrm{a}_{2} \mathrm{~b}_{2}=-0.003\right)$ were not different than zero ( -0.323 to 0.855 and -0.708 to 0.738 , respectively).

Similar analysis with the outcome of Medical Care Utilization scores revealed that mental distress symptoms (MDSx) directly affected Medical Care Utilization (MUQ) ( $c=4.46, p=.000)$. More specifically, participants with clinically meaningful levels of mental distress symptoms $(\mathrm{MDS} x=1)$ reported more medical care utilization than other participants and this relationship remained significant after accounting for both mediators ( $c^{\prime}=2.43, p=.000$; confidence intervals 1.317 to 3.549). Participants who reported clinically meaningful levels of mental distress symptoms $(\mathrm{MDS} x=1)$ reported both more fear of physiological sensations (AS-physical concerns) than other participants $(\operatorname{MDSx}=0)\left(\mathrm{a}^{1}=5.90, p=.000\right)$ and less tolerance of uncertainty $\left(\mathrm{a}^{2}=11.25, p=.000\right)$. $95 \%$ confidence intervals based on 10,000 bootstrap samples indicated that the indirect effect through AS-physical concerns $\left(a_{1} b_{1}=2.14\right)$, holding IUS constant, was entirely above zero ( 1.475 to 2.871). By contrast, the confidence intervals for IUS $\left(a_{2} b_{2}=-0.117\right)$ were not different than zero $(-0.729$ to 0.461$)$. In summary, mediation 
Table 3 Path coefficients for parallel mediation model for COVID Safety Behaviours (CSBC)

\begin{tabular}{lllllll}
\hline Path & \multicolumn{2}{l}{ COVID Safety Behaviours (DV) } & & & \\
\cline { 2 - 7 } & Effect & Boot-LLCI & Boot-UCLI & SE & $\mathrm{t}$ & p-value \\
\hline Total Effect & 1.668 & 0.629 & 2.707 & 0.529 & 3.155 & 0.002 \\
Direct Effect & 1.396 & 0.089 & 2.703 & 0.665 & 2.010 & 0.036 \\
IV-M1 (a1) & 5.943 & 4.500 & 6.886 & 0.480 & 12.383 & 0.000 \\
IV-M2 (a2) & 11.187 & 9.536 & 12.837 & 0.840 & 13.318 & 0.000 \\
M1-DV (b1) & 0.046 & -0.060 & 0.152 & 0.054 & 0.856 & 0.393 \\
M2-DV (b2) & 0.000 & -0.061 & 0.060 & 0.031 & -0.009 & 0.993 \\
Total Indirect Effect & 0.272 & -0.590 & 1.154 & 0.439 & & \\
IV-M1-DV (a1b1) & 0.275 & -0.323 & 0.855 & 0.298 & & \\
IV-M2-DV (a2b2) & 0.003 & -0.708 & 0.738 & 0.364 & & \\
\hline
\end{tabular}

Note: $I V$ mental distress symptoms, $D V$ COVID safety behaviours, $M 1$ anxiety sensitivity-physical concerns, $M 2$ intolerance of uncertainty. See Fig. 2

analyses showed that elevated mental distress symptoms yielded a direct effect on both COVID safety behaviours and medical care utilization, as well as an indirect effect on medical care utilization (but not safety behaviours) through AS-physical concerns (but not IU).

\section{Discussion}

Pandemics, such as COVID-19, are bound to generate fear and uncertainty given their unexpectedness, unpredictability, invisibility, and potential for harm. Greater fear and uncertainty can manifest in elevated levels of mental distress symptoms - anxiety,

Table 4 Path coefficients for parallel mediation model for Medical Care Utilization (MUQ)

\begin{tabular}{lllllll}
\hline Path & \multicolumn{2}{l}{ Medical Care Utilization (DV) } & & \\
\cline { 2 - 7 } & Effect & Boot-LLCI & Boot-UCLI & SE & $\mathrm{t}$ & p-value \\
\hline Total Effect & 4.459 & 3.501 & 5.408 & 0.483 & 9.235 & 0.000 \\
Direct Effect & 2.433 & 1.317 & 3.549 & 0.568 & 4.284 & 0.000 \\
IV-M1 (a1) & 5.900 & 4.951 & 6.848 & 0.483 & 12.223 & 0.000 \\
IV-M2 (a2) & 11.252 & 9.608 & 12.897 & 0.837 & 13.451 & 0.000 \\
M1-DV (b1) & 0.363 & 0.273 & 0.454 & 0.046 & 7.790 & 0.000 \\
M2-DV (b2) & -0.010 & -0.034 & 0.762 & 0.027 & -0.392 & 0.696 \\
Total Indirect Effect & 2.026 & 1.195 & 2.901 & 0.434 & & \\
IV-M1-DV (a1b1) & 2.142 & 1.475 & 2.871 & 0.356 & & \\
IV-M2-DV (a2b2) & -0.117 & -0.729 & 0.461 & 0.303 & & \\
\hline
\end{tabular}

Note: $I V$ mental distress symptoms, $D V$ medical care utilization, $M 1$ anxiety sensitivity-physical concerns, $M 2$ intolerance of uncertainty. See Fig. 3 


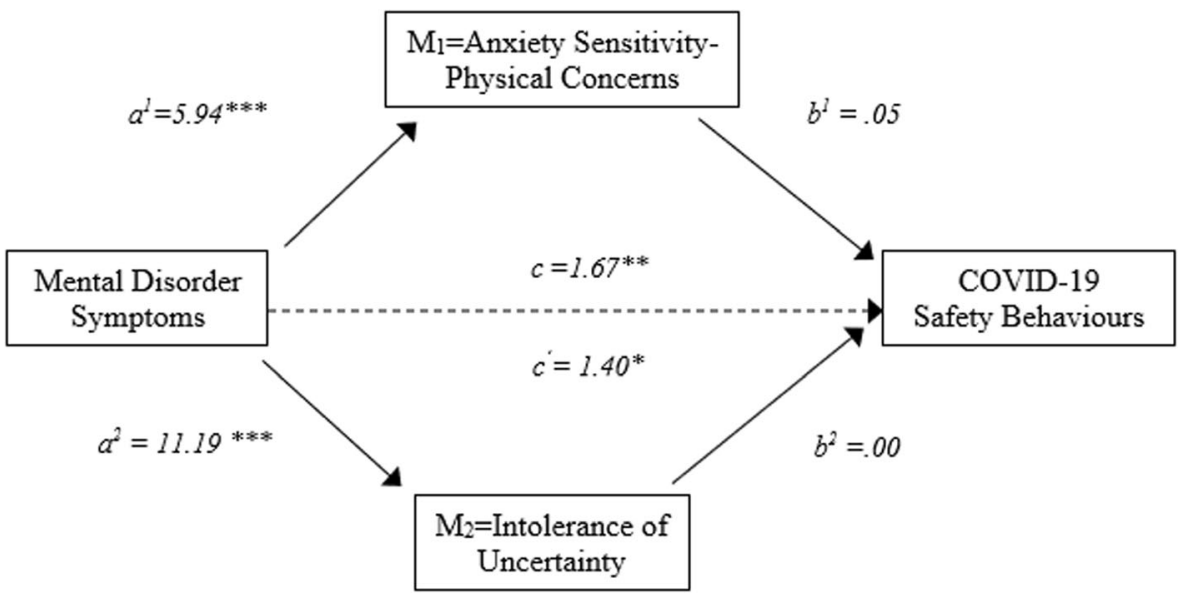

Fig. 2 Model of multiple parallel mediation analyses on COVID-19 safety behaviours. Note: Direct effect of mental distress symptoms and indirect effects via the physical concerns dimension of anxiety sensitivity and intolerance of uncertainty (adapted from Hayes, 2018)

stress, depression - as confirmed by recently released COVID-19 studies (Czeisler et al., 2020; Dozois and Mental Health Research Canada, 2020; Salari et al., 2020; Taylor, Landry, Paluszek, Fergus, et al., 2020b). In turn, greater mental distress symptoms can lead to greater demands on limited healthcare resources, both psychological and medical. While all people (the literal meaning of pan as in pandemic) are at risk for negative mental health impacts of pandemics, some individuals are at greater risk for impairment in functioning than others. In the present study, we examined the respective roles of two well-known transdiagnostic risk factors - AS-physical concerns and IU — in explaining some people's behavioural responses (safety behaviours and medical care utilization) to mental distress symptoms - anxiety, depression, and stress during the COVID-19 pandemic.

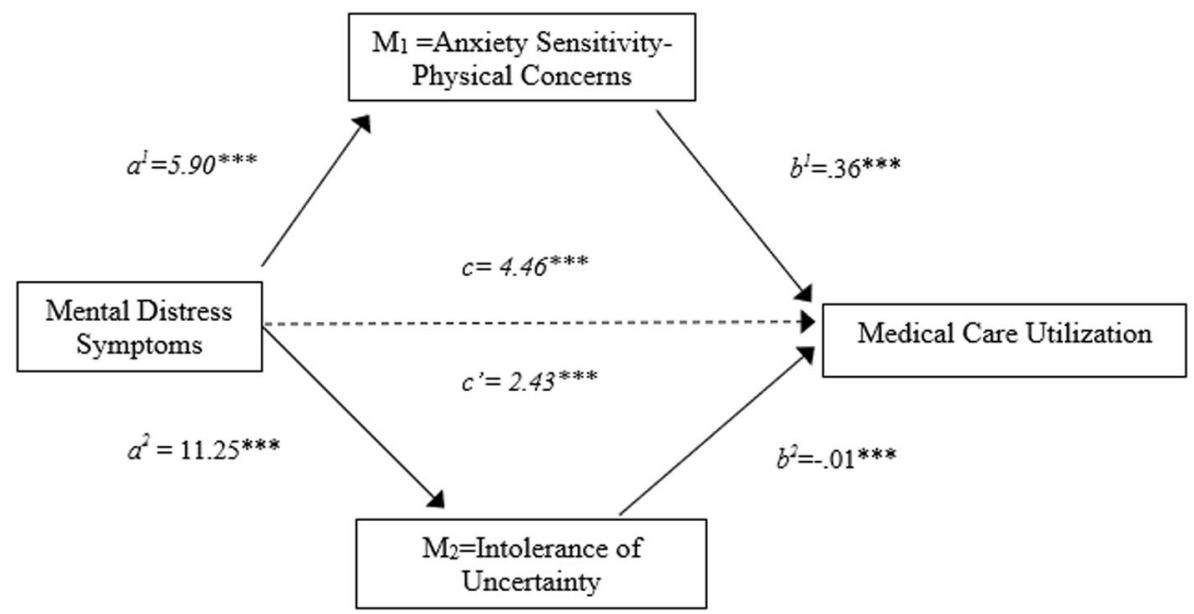

Fig. 3 Model of multiple parallel mediation analyses on medical care utilization. Note: Direct effect of mental distress symptoms on medical care utilization and indirect effects via the physical concerns dimension of anxiety sensitivity and intolerance of uncertainty (adapted from Hayes, 2018) 
Present participants were categorized into mental distress symptom groups (i.e., clinically meaningful symptom levels or not) based on their scores on standardized measures of anxiety (health, panic, general), depression, and stress. Given that the most conservative (extreme) cut-off scores were used to create the groups, it is noteworthy that almost half of the participants reported at least one clinically meaningful symptom. Anxiety symptoms figured most prominently, with almost two-thirds reporting concerning levels of general anxiety; over half reported concerning levels of depression, and one-third reported elevated stress. These findings attest to the significant mental health impact of pandemics generally and COVID-19 more specifically.

While it had been expected that anxiety and related symptoms would be elevated as compared to "normal" (non-pandemic), the first remarkable finding was the significant elevation in all symptoms as compared to the findings of previous pandemic studies (e.g., Blakey \& Abramowitz, 2017; Blakey et al., 2015; Wheaton et al., 2012). Indeed, the present sample revealed significantly greater concerns about the physical consequences of their arousal-related somatic sensations (AS-physical), greater intolerance of uncertainty, higher levels of both health and general anxiety, and depression and stress. There are some reasons to suppose that symptoms would be higher during COVID-19 as compared to other global health crises. Certainly, COVID-19 is the most virulent pathogen the world has faced since the 1918 influenza, for several reasons. First, COVID-19 not only kills the elderly or those with pre-existing health conditions, but healthy adults as well, resulting in a much higher fatality rate than the seasonal flu. Secondly, its rate of transmission is much higher and more insidious - an infected person can transmit it when pre-symptomatic, asymptomatic, or exhibiting only mild symptoms (Gates, 2020). This elevated level of threat may be driving anxiety about contracting the virus or about loved ones catching it. Thirdly, austere regulations, at a level unique to the current pandemic (e.g., significantly reduced in-person contact; Groarke et al., 2020; governmentally enforced social distancing policies; Lipton \& Steinhauer, 2020), also may be contributing to mental health issues as, for many, they have resulted in separation from loved ones (including sick loved ones) and financial hardships. Fourthly, unlike previous infections, limited access to COVID-19 vaccines accentuates anxiety surrounding the illness.

The present sample also reported concerning levels of panic anxiety with nearly $30 \%$ of participants reporting at least one panic attack in the past 2 weeks and over $5 \%$ reporting multiple attacks. Panic anxiety has not been assessed in previous pandemic studies although recent reports from India indicate that panic, along with anxiety, depression, sleep disturbances, and a sense of loneliness are increasing among the general population during the pandemic (Iqbal \& Dar, 2020; Roy et al., 2020). Interestingly, in the present study, a recent history ( 2 weeks) of panic attacks was the only mental distress symptom that was not significantly associated with COVID-19 safety behaviours. Of course, panic-related anxiety differs from other forms of anxiety (e.g., health, general) in that panic attacks are short bursts of intense fear that arise unexpectedly in response to a perceived threat in the moment. The activation of the fight-or-flight system includes increased heart rate, chest pain, and shortness of breath (American Psychiatric Association, 2013). Other forms of anxiety involve more chronic worry and apprehension about anticipated threats and can include a general feeling of uneasiness, irritability, restlessness, muscle tension, and fatigue. Engaging in safety behaviours (e.g., wearing a mask, using hand sanitizer, practicing physical distancing) 
involves more deliberative versus spontaneous actions. Moreover, it is possible that safety behaviours like wearing a mask could serve to exacerbate panic symptoms, so may inhibit the use of such safety measures when panic is elevated. Following a systematic review of the literature, Bakhit et al. (2020) found some evidence for potential adverse reactions to wearing a mask, such as increased dyspnea, but concluded the evidence was insufficient to justify mask exemptions. Future research could examine whether certain panic attack symptoms, such as respiratory, are more prevalent during the COVID-19 pandemic.

COVID-19 protocols that limit movement (e.g., quarantines, social distancing, home confinement) would contribute to heightened levels of mental distress symptoms. Lockdowns require that individuals restrict or surrender their physical contact with loved ones; adapt their routine to work from home, sometimes while simultaneously caring for their children who can no longer physically attend school; and relinquish many of their opportunities for socialization and other elements of their routine. Moreover, such restrictions prevent participation in many of the self-care activities that people utilize to attenuate symptoms of stress, anxiety, and depression. These activities can include travel, visits to hairdressers and spas, socializing with friends, and engaging in physical activity. Restrictions on the latter, via lack of access to recreational areas and fitness centres, may be particularly harmful given the myriad mental and physical health benefits of physical exercise (see Amatriain-Fernández et al., 2020).

Physical exercise is known to be beneficial for individuals with high AS, especially women (see DeWolfe et al., 2019). High AS individuals tend to avoid physical exercise as it triggers the physiological sensations that they fear, but decreasing AS through physical exercise has been shown to mediate reductions in anxious and depressed mood. CBT designed to target global AS with running as an interoceptive exposure (IE) component (CBT-IE; Watt \& Stewart, 2008) has been found to reduce AS levels in high AS women (Watt et al., 2006; Watt \& Stewart, 2008), as well as treatment-seeking adults (Olthuis et al., 2020). Effects have been found to last up to 14 weeks (Sabourin et al., 2015, 2016). Through repeated exposure to feared physiological sensations (via physical exercise) without anticipated catastrophic consequences (e.g., heart attack, loss of control, embarrassment), AS levels eventually subside.

Mediation analyses showed that participants with clinically meaningful levels of mental distress symptoms (anxiety, depression, stress) had higher levels of both AS and $\mathrm{IU}$ and were more apt to engage in safety behaviours and medical care utilization than other participants. Elevated mental distress symptoms yielded a direct effect on both COVID safety behaviours and medical care utilization but also an indirect effect on the latter through AS-physical concerns (but not IU). In other words, a specific fear of the physical consequences of physiological arousal (AS-physical concerns), as opposed to a more general fear of uncertainty, explained why some people were more apt to seek out medical information and/or attention than others with similar symptom profiles (i.e., elevated mental distress symptoms).

Individuals with high AS-physical concerns are inclined to attend more closely to physical sensations and to catastrophize about the meaning of those sensations, thinking they signify imminent harm, such as a heart attack. In the throes of a pandemic, people are encouraged to assess their bodily symptoms (aches and pains, fever, shortness of breath, sore throat, headache) on a regular basis. For individuals with prominent AS-physical concerns, this could activate a cycle of elevated attention to 
bodily sensations, resulting in increased anxiety (and related symptoms) and greater need for medical reassurance which, in turn, can reinforce unreasonable fears and further elevate alarm. Tailoring CBT-IE interventions to target high AS-physical concerns could yield positive effects for mental distress symptoms and, perhaps, reduce unnecessary healthcare utilization during the COVID-19 pandemic.

Recently, Norr et al. (2015) investigated AS and IU as potential risk factors for "cyberchondria". Cyberchondria is a phenomenon whereby online medical information seeking contributes to a positive feedback loop of escalating physical symptom concerns. Norr et al. (2014) found that both AS and IU (inhibitory vs. prospective) predicted unique variance associated with cyberchondria above and beyond each other and health anxiety. The cross-sectional nature of the sample precluded conclusions about the temporal relationship among the variables, but it was suggested that AS and cyberchondria may have a mutually escalating transactional relationship, which would be consistent with findings that exposure to medical information websites could serve to maintain elevated levels of AS (Norr et al., 2014).

Wheaton et al. (2020) found that IU partially accounted for connections between fear of COVID-19 and OCD and health anxiety symptoms. While the present study did not examine OCD symptoms, results indicate that IU does not influence either medical care utilization or safety behaviours. Wheaton et al.'s data was collected in early March 2020, when COVID-19 was just beginning to spread, and little was known of its symptoms or severity. Therefore, uncertainty concerning the virus may have been higher and thus the effects of intolerance of uncertainty more pronounced. Conversely, the present study collected data between late April and July, when more was known about COVID-19, including its physical symptoms, which might explain the influence of AS but not IU in present findings. Furthermore, Wheaton et al. themselves note that IU may overlap with other factors such as AS in variance accounted for and recommended that future research examine IU in conjunction with AS, which the present study did, finding that AS (vs. IU) indirectly influenced medical care utilization. Present findings make sense in light of Tull et al.'s (2020) findings. Tull et al. found that IU only moderated the association between COVID-19 affective risk assessments and health anxiety at low and mean levels - there was no significant association at high levels of IU. Given that levels of IU in the present sample were significantly higher than normative IU scores, this may explain why IU did not indirectly mediate either medical care utilization or safety behaviours.

While the short-term impacts of elevated levels of mental distress symptoms appear obvious - greater distress, impairment in functioning, overutilization of healthcare resources - the longer-term implications are equally concerning. While it was expected that anxiety levels would be elevated during the pandemic, levels in the present study were even higher than has been found during other similar health crises (pandemic, epidemic) (Blakey \& Abramowitz, 2017; Blakey et al., 2015). Over time, most people will acclimatize to the "new normal" and anxiety levels may decrease, but depression levels are expected to rise as the pandemic continues (see Dozois and Mental Health Research Canada, 2020). The losses associated with COVID-19 financial, occupational, social, health, life - could fuel depression for many people. During the SARS epidemic, self-isolation was found to predict high rates of depression (Liu et al., 2012). This may be due to individuals' restricted ability to partake in activities from which they usually derive pleasure, which could promulgate a 
downward spiral (Dozois and Mental Health Research Canada, 2020). The current pandemic also has resulted in considerable loneliness for many, precipitated by public health measures such as lockdown and physical distancing. Loneliness and isolation can have deleterious effects on mental health, including as a factor for depression (Dozois and Mental Health Research Canada, 2020).

Results of the present study must be considered in light of the following limitations. First, all of the measures used to assess mental health symptoms were self-report measures as opposed to a more formal structured assessment of symptoms like the Structured Clinical Interview for Disorders (SCID; First et al., 2016). All of the measures, however, demonstrated reliability and validity and reports of mental health symptoms were positively associated with AS-physical scores, IU, COVID-19 safety measures, and more medical utilization, as would be expected by both theory and the previous research. Moreover, there is some evidence to suggest that individuals can accurately report their mental health symptoms (see Stuart et al., 2014). Second, the present study did not assess current illness status (mental or physical diagnoses), which may have been important to consider because if any participants were experiencing COVID-19 symptoms it very likely would have inflated their scores on most of the measures. Third, it is possible that the lack of mediation through IU resulted from our parallel mediation approach. Although testing correlated mediators at the same time serves to disentangle spurious and epiphenomenal association from potential causal association, it comes at the cost of reduced power for tests of indirect effects. On the other hand, testing AS-physical concerns and IU in a simple mediation model would have its own limitations (see Hayes, 2018). Also, we did not examine IU subscales. It is possible that the IU inhibitory dimension (vs. prospective dimension, see Norr et al., 2014) could further explicate relations between mental distress symptoms and behavioural responding and possibly yield an avoidance effect.

The incidence of infectious disease outbreaks has increased significantly over the past 30 years (Candeias \& Morhard, 2018). This elevates the imperative to better understand the physical and mental healthcare impacts. Moynihan et al. (2020) suggest that the current pandemic may yield the paradoxical effect of making healthcare delivery more efficient by reducing the overuse of resources ("too much medicine"). They suggest that this may serve to enhance sustainability and equity in the system. Certainly, with healthcare resources at a premium, more efficient allocation of scarce resources to those at greatest risk and in greatest need is important. As in non-pandemic times, however, the challenge is directing individuals to appropriate care and resources. Research shows that people are more apt to seek out medical (vs. psychological) services for mental health problems (see Murdoch et al., 2015). This is particularly true for anxiety symptoms, which contributes to higher rates of initial medical care utilization and longer delays in accessing effective psychological interventions with anxiety (vs. mood) disorder populations (Deacon et al., 2008). Panic attacks, in particular, tend to be viewed as a medical condition in need of medical attention. Indeed, it has been estimated that over $75 \%$ of people presenting to emergency rooms with noncardiac chest pain do so after a panic attack (see Gallagher \& Watt, 2019). Few studies have examined panic anxiety during epidemics or pandemics. Future research with attention to panic symptom subtypes could be helpful.

This study's findings have practical significance. Higher rates of medical care utilization due to COVID-19-related symptoms are straining the healthcare system. 
Public policy measures (e.g., wearing masks, social distancing, quarantining) are intended to "flatten the curve" or limit the number of cases so as to save lives and protect limited healthcare resources. Early and appropriate intervention with mental health problems could yield valuable dividends. Identifying individuals at increased risk for mental distress symptoms and redirecting them away from medical services to empirically validated psychological interventions, such as CBT-IE for AS-physical concerns, could reduce mental distress symptoms and medical care utilization. In addition, it is important that the public receive more information about mental health risks during a pandemic and what they can do to mitigate that risk. The public also should be encouraged to look for innovative ways of maintaining a regular physical exercise regimen, despite lockdowns and restrictions, for the sake of their mental health. Future research should examine people's physical exercise habits during the pandemic and how it relates to their mental health status.

\section{Declarations}

Conflict of Interest The authors declare no competing interests.

\section{References}

Abramowitz, J., Deacon, B. J., \& Valentiner, D. (2007). The Short Health Anxiety Inventory: Psychometric properties and construct validity in a non-clinical sample. Cognitive Therapy and Research, 31(6), 871883. https://doi.org/10.1007/s10608-006-9058-1.

Alberts, N. M., Hadjistavropoulos, H. D., Jones, S. L., \& Sharpe, D. (2013). The Short Health Anxiety Inventory: A systematic review and meta-analysis. Journal of Anxiety Disorders, 27(1), 68-78. https:// doi.org/10.1016/j.janxdis.2012.10.009.

Allan, N. P., Norr, A. M., Capron, D. W., Raines, A. M., Zvolensky, M. J., \& Schmidt, N. B. (2015). Specific associations between anxiety sensitivity dimensions and fear and distress dimensions of emotional distress disorders. Journal of Psychopathology and Behavioral Assessment, 37(1), 67-78. https://doi.org/10.1007/ s10862-014-9437-y.

Amatriain-Fernández, S., Murillo-Rodríguez, E. S., Gronwald, T., Machado, S., \& Budde, H. (2020). Benefits of physical activity and physical exercise in the time of pandemic. Psychological Trauma Theory Research Practice and Policy, 12(S1), S264-S266. https://doi.org/10.1037/tra0000643.

American Psychiatric Association. (2013). Diagnostic and statistical manual of mental disorders: DSM-5 (5th ed.). American Psychiatric Association.

B.C. Centre for Disease Control (2020). COVID-19. Retrieved from http://www.bccdc.ca/health-info/ diseases-conditions/covid-19

Bakhit, M., Krzyzaniak, N., Scott, A. M., Clark, J., Glasziou, P., \& Del Mar, C. (2020). Downsides of face masks and possible mitigation strategies: a systematic review and meta-analysis. MedRxiv. https://doi.org/ 10.1101/2020.06.16.20133207.

Balderston, N. L., Schultz, D. H., \& Helmstetter, F. J. (2013). The effect of threat on novelty evoked amygdala responses. PLoS One, 8(5), e63220. https://doi.org/10.1371/journal.pone.0063220.

Barsky, A. J., Ettner, S. L., Horsky, J., \& Bates, D. W. (2001). Resource utilization of patients with hypochondriacal health anxiety and somatization. Medical Care, 39, 705-715. https://doi.org/10.1097/ 00005650-200107000-00007.

Blakey, S. M., \& Abramowitz, J. S. (2017). Psychological predictors of health anxiety in response to the Zika virus. Journal of Clinical Psychology in Medical Settings, 24(3-4), 270-278. https://doi.org/10.1007/ s10880-017-9514-y.

Blakey, S. M., Reuman, L., Jacoby, R. J., \& Abramowitz, J. S. (2015). Tracing “fearbola": Psychological predictors of anxious responding to the threat of Ebola. Cognitive Therapy and Research, 39(6), 816-825. https://doi.org/10.1007/s10608-015-9701-9. 
Brand, J., McKay, D., Wheaton, M. G., \& Abramowitz, J. S. (2013). The relationship between obsessive compulsive beliefs and symptoms, anxiety and disgust sensitivity, and Swine flu fears. Journal of Obsessive-Compulsive and Related Disorders, 2(2), 200-206. https://doi.org/10.1016/j.jocrd.2013.01. 007.

Buhr, K., \& Dugas, M. J. (2009). The role of fear of anxiety and intolerance of uncertainty in worry: An experimental manipulation. Behaviour Research and Therapy, 47(3), 215-223. https://doi.org/10.1016/j. brat.2008.12.004.

Candeias, V., \& Morhard, R. (2018). The human costs of epidemics are going down but the economic costs are going up. Here's why. World Economic Forum. Retrieved from https://www.weforum.org/agenda/ 2018/05/how-epidemics-infect-the-global-economy-and-what-to-do-about-it/

Carleton, R. N. (2016). Fear of the unknown: One fear to rule them all? Journal of Anxiety Disorders, 41, 521. https://doi.org/10.1016/j.janxdis.2016.03.011.

Carleton, R. N., Norton, M. A., \& Asmundson, G. J. G. (2007). Fearing the unknown: A short version of the intolerance of uncertainty scale. Journal of Anxiety Disorders, 21, 105-117. https://doi.org/10.1016/j. janxdis.2006.03.014.

Carleton, R. N., Mulvogue, M. K., Thibodeau, M. A., McCabe, R. E., Antony, M. M., \& Asmundson, G. J. G. (2012). Increasingly certain about uncertainty: Intolerance of uncertainty across anxiety and depression. Journal of Anxiety Disorders, 26(3), 468-479. https://doi.org/10.1016/j.janxdis.2012.01.011.

Centers for Disease Control and Prevention (2020). Coronavirus Disease 2019. Retrieved from https://www. cdc.gov/media/dpk/diseases-and-conditions/coronavirus/coronavirus-2020.html

Conroy, R. M., Smyth, O., Siriwardena, R., \& Fernandes, P. (1999). Health anxiety and characteristics of selfinitiated general practitioner consultations. Journal of Psychosomatic Research, 46, 45-50. https://doi. org/10.1016/S0022-3999(98)00066-X.

Creed, F. (2011). The relationship between somatic symptoms, health anxiety, and outcome in medical outpatients. Psychiatric Clinics of North America, 34, 545-564. https://doi.org/10.1016/j.psc.2011.05. 001.

Czeisler, M. E., Lane, R. I., Petrosky, E., et al. (2020). Mental health, substance use, and suicidal ideation during the COVID-19 pandemic - United States, June 24-30, 2020. MMWR. Morbidity and Mortality Weekly Report, 69, 1049-1057. https://doi.org/10.15585/mmwr.mm6932a1.

Deacon, B., Lickel, J., \& Abramowitz, J. S. (2008). Medical utilization across the anxiety disorders. Journal of Anxiety Disorders, 22(2), 344-350. https://doi.org/10.1016/j.janxdis.2007.03.004.

DeWolfe, C., Watt, M. C., Romero, P., \& Stewart, S. H. (2019). Gender differences in physical activity are partially explained by anxiety sensitivity in post-secondary students. Journal of American College Health, $68(3), 219-222$.

Dozois, D. J. A., \& Mental Health Research Canada. (2020). Anxiety and depression in Canada during the COVID-19 pandemic: A national survey. Canadian Psychology/Psychologie Canadienne. https://doi.org/ 10.1037/cap0000251.

Dugas, M. J., Ladouceur, R., Léger, E., Freeston, M. H., Langolis, F., Provencher, M. D., \& Boisvert, J.-M. (2003). Group cognitive-behavioral therapy for generalized anxiety disorder: Treatment outcome and long-term follow-up. Journal of Consulting and Clinical Psychology, 71(4), 821-825. https://doi.org/10. 1037/0022-006X.71.4.821.

Fergus, T. A., \& Bardeen, J. R. (2013). Anxiety sensitivity and intolerance of uncertainty: Evidence of incremental specificity in relation to health anxiety. Personality and Individual Differences, 55(6), 640644. https://doi.org/10.1016/j.paid.2013.05.016.

Fergus, T. A., \& Valentiner, D. P. (2010). Disease phobia and disease conviction are separate dimensions underlying hypochondriasis. Journal of Behavior Therapy and Experimental Psychiatry, 41(4), 438-444. https://doi.org/10.1016/j.jbtep.2010.05.002.

Fergus, T., Bardeen, J., Gratz, K., Fulton, J., \& Tull, M. (2015). The contribution of health anxiety to retrospectively-recalled emergency department visits within a sample of patients in residential substance abuse treatment. Cognitive Behaviour Therapy, 44, 1-8. https://doi.org/10.1080/16506073.2014.946077.

First, M. B., Williams, J. B. W., Karg, R. S., \& Spitzer, R. L. (2016). Structured Clinical Interview for DSM-5 Disorders, Clinician Version (SCID-5-CV). American Psychiatric Association.

Gallagher, C. E., \& Watt, M. C. (2019). Mental health literacy in a sample of Canadian adults. Canadian Journal of Behavioural Science / Revue canadienne des sciences du comportement, 51(3), 171-180. https://doi.org/10.1037/cbs0000129.

Gates, B. (2020). Responding to Covid-19 - A once-in-a-century pandemic? New England Journal of Medicine, 382, 1677-1679. https://doi.org/10.1056/NEJMp2003762. 
Gerrior, K. G., Watt, M. C., Weaver, A. D., \& Gallagher, C. E. (2015). The role of anxiety sensitivity in the sexual functioning of young women. Sexual and Relationship Therapy, 30(3), 351-363. https://doi.org/ 10.1080/14681994.2015.1018885.

Gosselin, P., Ladouceur, R., Morin, C. M., Dugas, M. J., \& Baillargeon, L. (2006). Benzodiazepine discontinuation among adults with GAD: A randomized trial of cognitive-behavioral therapy. Journal of Consulting and Clinical Psychology, 74(5), 908-919. https://doi.org/10.1037/0022-006X.74.5.908.

Groarke, J. M., Berry, E., Graham-Wisener, L., McKenna Plumley, P. E., McGlinchey, E., \& Armour, C. (2020). Loneliness in the UK during the COVID-19 pandemic: Cross-sectional results from the COVID19 Psychological Wellbeing Study. PLoS One, 15(9) https://doi-org.libproxy.stfx.ca/10.1371/journal. pone.0239698.

Hayes, A. F. (2013). Methodology in the social sciences. In Introduction to mediation, moderation, and conditional process analysis: A regression-based approach. Guilford Press.

Hayes, A. F. (2018). Partial, conditional, and moderated moderated mediation: Quantification, inference, and interpretation. Communication Monographs, 85, 4-40.

Henry, J. D., \& Crawford, J. R. (2005). The short-form version of the Depression Anxiety Stress Scales (DASS-21): Construct validity and normative data in a large non-clinical sample. British Journal of Clinical Psychology, 44(2), 227-239. https://doi.org/10.1348/014466505X29657.

Horenstein, A., Rogers, A. H., Bakhshaie, J., Zvolensky, M. J., \& Heimberg, R. G. (2019). Examining the role of anxiety sensitivity and intolerance of uncertainty in the relationship between health anxiety and likelihood of medical care utilization. Cognitive Therapy and Research, 43(1), 55-65. https://doi.org/ 10.1007/s10608-018-9980-z.

Iqbal, N., \& Dar, K. A. (2020). Coronavirus disease (COVID-19) pandemic: Furnishing experiences from India. Psychological Trauma Theory Research Practice and Policy, 12(S1), S33-S34. https://doi.org/10. 1037/tra0000770.

Lipton, E., Steinhauer, J. (2020). The untold story of the birth of social distancing. The New York Times. Retrieved from https://www.nytimes.com/2020/04/22/us/politics/social-distancing-coronavirus.html

Liu, X., Kakade, M., Fuller, C. J., Fan, B., Fang, Y., Kong, J., ..., Wu, P. (2012). Depression after exposure to stressful events: Lessons learned from the severe acute respiratory syndrome epidemic. Comprehensive Psychiatry, 53, 15-23. https://doi.org/10.1016/j.comppsych.2011.02.003

Lovibond, S. H., \& Lovibond, P. F. (1995). Manual for the Depression Anxiety \& Stress Scales (2nd ed.). Psychology Foundation.

McKay, D., Yang, H., Elhai, J., \& Asmundson, G. (2020). Anxiety regarding contracting COVID-19 related to interoceptive anxiety sensations: The moderating role of disgust propensity and sensitivity. Journal of Anxiety Disorders. https://doi.org/10.1016/j.janxdis.2020.102233.

Moynihan, R., Johansson, M., Maybee, A., Lang, E., \& Légaré, F. (2020). Covid-19: An opportunity to reduce unnecessary healthcare. $B M J, 370, \mathrm{~m} 2752$. https://doi.org/10.1136/bmj.m2752.

Murdoch, D. D., Gregory, A., \& Eggleton, J. M. (2015). Why psychology? An investigation of the training in psychological literacy in nursing, medicine, social work, counselling psychology, and clinical psychology. Canadian Psychology/Psychologie Canadienne, 56(1), 136-146. https://doi.org/10.1037/a0038191.

Norr, A. M., Capron, D. W., \& Schmidt, N. B. (2014). Medical information seeking: Impact on risk for anxiety psychopathology. Journal of Behavior Therapy and Experimental Psychiatry, 45(3), 402-407. https://doi.org/10.1016/j.jbtep.2014.04.003.

Norr, A. M., Albanese, B. J., Oglesby, M. E., Allan, N. P., \& Schmidt, N. B. (2015). Anxiety sensitivity and intolerance of uncertainty as potential risk factors for cyberchondria. Journal of Affective Disorders, 174, 64-69. https://doi.org/10.1016/j.jad.2014.11.023.

Norton, P. J., Zvolensky, M. J., Bonn-Miller, M. O., Cox, B. J., \& Norton, G. R. (2008). Use of the Panic Attack Questionnaire-IV to assess non-clinical panic attacks and limited symptom panic attacks in student and community samples. Journal of Anxiety Disorders, 22(7), 1159-1171. https://doi.org/10.1016/j. janxdis.2007.12.002.

O’Bryan, E. M., \& McLeish, A. C. (2017). An examination of the indirect effect of intolerance of uncertainty on health anxiety through anxiety sensitivity physical concerns. Journal of Psychopathology and Behavioral Assessment, 39(4), 715-722. https://doi.org/10.1007/s10862-017-9613-y.

Olatunji, B. O., \& Wolitzky-Taylor, K. B. (2009). Anxiety sensitivity and the anxiety disorders: A metaanalytic review and synthesis. Psychological Bulletin, 135(6), 974-999. https://doi.org/10.1037/ a0017428.

Olatunji, B. O., Wolitzky-Taylor, K. B., Elwood, L., Connolly, K., Gonzales, B., \& Armstrong, T. (2009). Anxiety sensitivity and health anxiety in a nonclinical sample: Specificity and prospective relations with clinical stress. Cognitive Therapy and Research, 33(4), 416-424. https://doi.org/10.1007/s10608-0089188-8. 
Olthuis, J. V., Watt, M. C., \& Stewart, S. H. (2014). Anxiety Sensitivity Index (ASI-3) subscales predict unique variance in anxiety and depressive symptoms. Journal of Anxiety Disorders, 28(2), 115-124. https://doi.org/10.1016/j.janxdis.2013.04.009.

Olthuis, J. V., Watt, M. C., Mackinnon, S. P., \& Stewart, S. H. (2015). CBT for high anxiety sensitivity: Alcohol outcomes. Addictive Behaviors, 46, 19-24. https://doi.org/10.1016/j.addbeh.2015.02.018.

Olthuis, J. V., Watt, M. C., DeWolfe, C., Connell, E., Wright, E., \& Sevigny, L. (2020). Learn to run for anxiety sensitivity: A feasibility study of a short-term, accessible physical exercise intervention. Women in Sport and Physical Activity, 28, 151-160.

Rask, C. U., Munkholm, A., Clemmensen, L., Rimvall, M. K., Ørnbøl, E., Jeppesen, P., \& Skovgaard, A. M. (2016). Health anxiety in preadolescence-associated health problems, healthcare expenditure, and continuity in childhood. Journal of Abnormal Child Psychology, 44(4), 823-832. https://doi.org/10.1007/ s10802-015-0071-2.

Reiss, S., \& McNally, R. J. (1985). Expectancy model of fear. In S. Reiss \& R. R. Bootzin (Eds.), Theoretical issues in behavior therapy (pp. 107-121). Academic Press.

Renjan, V., McEvoy, P. M., Handley, A. K., \& Fursland, A. (2016). Stomaching uncertainty: Relationships among intolerance of uncertainty, eating disorder pathology, and comorbid emotional symptoms. Journal of Anxiety Disorders, 41, 88-95. https://doi.org/10.1016/j.janxdis.2016.03.008.

Roy, D., Tripathy, S., Kar, S. K., Sharma, N., Verma, S. K., \& Kaushal, V. (2020). Study of knowledge, attitude, anxiety \& perceived mental healthcare need in Indian population during COVID-19 pandemic. Asian Journal of Psychiatry, 51, 102083-102087. https://doi.org/10.1016/j.ajp.2020.102083.

Rubin, G. J., Amlôt, R., Page, L., \& Wessely, S. (2009). Public perceptions, anxiety, and behaviour change in relation to the swine flu outbreak: Cross sectional telephone survey. BMJ [British Medical Journal], 339(7713). https://doi.org/10.1136/bmj.b2651.

Sabourin, B. C., Hilchey, C. A., Lefaivre, M.-J., Watt, M. C., \& Stewart, S. H. (2011). Why do they exercise less? Barriers to exercise in high-anxiety-sensitive women. Cognitive Behaviour Therapy, 40(3), 206215. https://doi.org/10.1080/16506073.2011.573572.

Sabourin, B. C., Stewart, S. H., Watt, M. C., \& Krigolson, O. E. (2015). Running as interoceptive exposure for decreasing anxiety sensitivity: Replication and extension. Cognitive Behaviour Therapy, 44(4), 264-274. https://doi.org/10.1080/16506073.2015.1015163.

Sabourin, B. C., Watt, M. C., Krigolson, O. E., \& Stewart, S. H. (2016). Two interventions decrease anxiety sensitivity among high anxiety sensitive women: Could physical exercise be the key? Journal of Cognitive Psychotherapy, 30(2), 131-146. https://oi.org/10.1891/0889-8391.30.2.131.

Salari, N., Hosseinian-Far, A., Jalali, R., Vaisi-Raygani, A., Rasoulpoor, S., Mohammadi, M., Rasoulpoor, S., \& Khaledi-Paveh, B. (2020). Prevalence of stress, anxiety, depression among the general population during the COVID-19 pandemic: a systematic review and meta-analysis. Globilization and Health, 16, 57. https://doi.org/10.1186/s12992-020-00589-w.

Salkovskis, P. M., Rimes, K. A., Warwick, H. M. C., \& Clark, D. M. (2002). The Health Anxiety Inventory: Development and validation of scales for the measurement of health anxiety and hypochondriasis. Psychological Medicine, 32(5), 843-853. https://doi.org/10.1017/S0033291702005822.

Stuart, A. L., Pasco, J. A., Jacka, F. N., Brennan, S. L., Berk, M., \& Williams, L. J. (2014). Comparison of self-report and structured clinical interview in the identification of depression. Comprehensive Psychiatry, 55(4), 866-869. https://doi.org/10.1016/j.comppsych.2013.12.019.

Taha, S., Matheson, K., Cronin, T., \& Anisman, H. (2014). Intolerance of uncertainty, appraisals, coping, and anxiety: The case of the 2009 H1N1 pandemic. British Journal of Health Psychology, 19(3), 592-605. https://doi.org/10.1111/bjhp.12058.

Taylor, S., Zvolensky, M. J., Cox, B. J., Deacon, B., Heimberg, R. G., Ledley, D. R., Abramowitz, J. S., Holaway, R. M., Sandin, B., Stewart, S. H., Coles, M., Eng, W., Daly, E. S., Arrindell, W. A., Bouvard, M., \& Cardenas, S. J. (2007). Robust dimensions of anxiety sensitivity: Development and initial validation of the Anxiety Sensitivity Index-3. Psychological Assessment, 19(2), 176-188. https://doi. org/10.1037/1040-3590.19.2.176.supp(Supplemental).

Taylor, S., Landry, C. A., Paluszek, M. M., \& Asmundson, G. J. G. (2020a). Reactions to COVID-19: Differential predictors of distress, avoidance, and disregard for social distancing. Journal of Affective Disorders, 277, 94-98. https://doi.org/10.1016/j.jad.2020.08.002.

Taylor, S., Landry, C. A., Paluszek, M. M., Fergus, T. A., McKay, D., \& Asmundson, G. J. G. (2020b). COVID stress syndrome: Concept, structure, and correlates. Depression and Anxiety, 37(8), 706-714. https://doi.org/10.1002/da.23071.

Toffolo, M. B. J., van den Hout, M. A., Engelhard, I. M., Hooge, I. T. C., \& Cath, D. C. (2014). Uncertainty, checking, and intolerance of uncertainty in subclinical obsessive compulsive disorder: An extended 
replication. Journal of Obsessive-Compulsive and Related Disorders, 3(4), 338-344. https://doi.org/10. 1016/j.jocrd.2014.08.004.

Tull, M. T., Barbano, A. C., Scamaldo, K. M., Richmond, J. R., Edmonds, K. A., Rose, J. P., \& Gratz, K. L. (2020). The prospective influence of COVID-19 affective risk assessments and intolerance of uncertainty on later dimensions of health anxiety. Journal of Anxiety Disorders, 75, 102290. https://doi.org/10.1016/j. janxdis.2020.102290.

Watt, M. C., \& Stewart, S. H. (2008). Overcoming the fear of fear: How to reduce anxiety sensitivity. New Harbinger Publications, Inc..

Watt, M. C., McWilliams, L. A., \& Campbell, A. G. (2005). Relations between anxiety sensitivity and attachment style dimensions. Journal of Psychopathology and Behavioral Assessment, 27(3), 191-200. https://doi.org/10.1007/s10862-005-0635-5.

Watt, M. C., Stewart, S. H., Lefaivre, M. J., \& Uman, L. S. (2006). A brief cognitive-behavioral approach to reducing anxiety sensitivity decreases pain-related anxiety. Cognitive Behaviour Therapy, 35(4), 248256. https://doi.org/10.1080/16506070600898553.

Wheaton, M. G., Abramowitz, J. S., Berman, N. C., Fabricant, L. E., \& Olatunji, B. O. (2012). Psychological predictors of anxiety in response to the H1N1 (swine flu) pandemic. Cognitive Therapy and Research, 36(3), 210-218. https://doi.org/10.1007/s10608-011-9353-3.

Wheaton, M. G., Messner, G. R., \& Marks, J. B. (2020). Intolerance of uncertainty as a factor linking obsessive-compulsive symptoms, health anxiety and concerns about the spread of the novel coronavirus (COVID-19) in the United States. Journal of Obsessive-Compulsive and Related Disorders, 28, 100605. https://doi.org/10.1016/j.jocrd.2020.100605.

Wong, L. P., \& Sam, I.-C. (2011). Behavioral responses to the influenza A(H1N1) outbreak in Malaysia. Journal of Behavioral Medicine, 34(1), 23-31. https://doi.org/10.1007/s10865-010-83-7.

World Health Organization. (2021). WHO Coronavirus Disease (COVID-19) Dashboard. Retrieved from https://covid19.who.int/. Accessed 10 Apr 2021.

Wright, K. D., Lebell, M. A. N. A., \& Carleton, R. N. (2016). Intolerance of uncertainty, anxiety sensitivity, health anxiety, and anxiety disorder symptoms in youth. Journal of Anxiety Disorders, 41, 35-42. https:// doi.org/10.1016/j.janxdis.2016.04.011.

Publisher's Note Springer Nature remains neutral with regard to jurisdictional claims in published maps and institutional affiliations. 